\section{Minor Constituents and Trace Elements in Negev Phosphate Rocks}

In the course of research on Negev phosphate rock, attention was directed to the presence of minor constituents and trace elements in the rock.

The analytical work involved in identifying these was considerable, as many of the methods in general use are not applicable when large amounts of phosphate ions are present. Even if the phosphate does not interfere, trace elements are sometimes present in amounts smaller than those required for detection by standard methods, and very often laborious separations were necessary in order to obtain the element in the pure form required for analysis.

Qualitative spectrographic analysis has revealed the presence of the following elements : aluminium, silver, arsenic, barium, calcium, cadmium, chromium, copper, iron, fluorine, potassium, magnesium, manganese, sodium, nickel, lead, titanium, uranium, vanadium and zinc.

Most of the elements detected by spectrographic analysis or by other means were determined quantitatively. Results were as follows (per cent) : aluminium, 0.1 ; arsenic-203, 0.002-0.004; chlorine, $0.09-1.3$; chromium, 0.015-0.05; copper, 0.0005; iron, $0.3-1.5$; magnesium, 0.3 ; nickel, 0.003 ; lead, 0.0005 ; silica, $0.1-0.8$; sulphate, $0.06-0.3$; sulphide, $0.012-0.016$; titanium monoxide, $0.06-$ 0.16 ; uranium, $0.005-0.015$; vanadium, 0.03 ; zinc, 0.0005 ; and organic matter, 0.1-0.7.

These results are in very good agreement with the results reported by Hill, Marshall and Jacob ${ }^{1}$ from a survey analysis of minor. metallic constituents of many phosphate rock samples originating from various areas in the United States.

Uranium was determined fluorometrically by the method of Price, Ferretti and Schwartz ${ }^{2}$ and by that of Yeaman ${ }^{3}$. The uranium content of Negev phosphate rocks is almost identical with that of phosphorites from Algeria, Tunisia and Egypt : 0.0040.016 per cent as reported by Davidson and Atkin*. Florida phosphates, as reported by the latter authors, may have a considerably higher uranium concentration, 0.001-0.15 per cent. Phosphorite from Morocco contains, according to Lenoble ${ }^{5}, 0.01-$ 0.06 per cent uranium.

Uranium has also been determined by $\beta$-activity measurements, using a Geiger counter, and comparing the activity with that of calcium phosphate samples containing known amounts of uranium.

A considerable number of samples from different locations in the Negev were analysed by this method, and on plotting concentration of uranium against

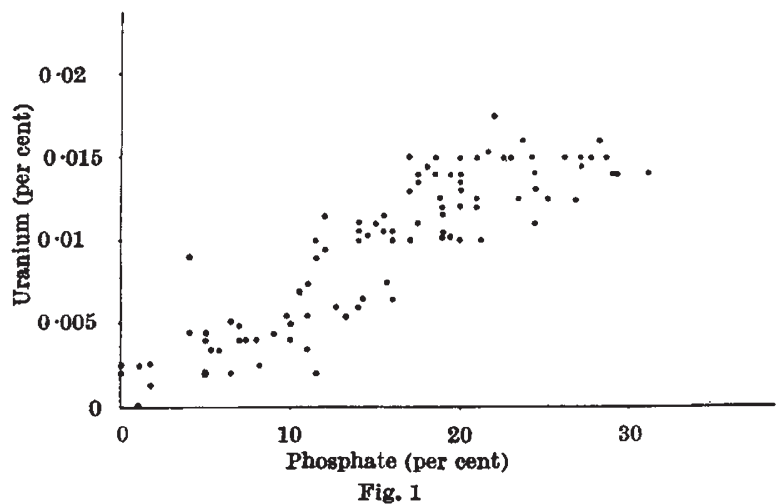

concentration of phosphate (Fig. I) a direct relationship was found between the two. This is in partial agreement with the data given by Thompson ${ }^{6}$ in his paper on distribution of uranium in rich phosphate beds of the phosphoria formation. The latter, however, found a poor uranium-phosphate correlation in samples containing smaller amounts of uranium, while our results show good correlation in the low concentration zone as well. This is probably due to the lower concentration of organic matter in our samples.

Thanks are due to Dr. M. Berl (Research Department of the Ministry of Defence), who made most of the chemical determinations, and to Mrs. I. Leviatan (Israel Atomic Energy Commission) for carrying out spectrographic determinations.

Israel Atomic Energy Commission.

E. FoA

$$
\text { April } 8 .
$$

1 Hill, W. L., Marshall, H. L., and Jacob, K. D., Indust. Eng. Chem., 24, 1306 (1932).

'Price, G. R., Ferretti, R. J., and Schwartz, S., U.S. A.E.C. Rep. $C C=2985$ (1945).

' Yeaman, M. D. U.S. A.E.C. Rep. DOW-65 (1951)

- Davidson, C. F., and Atkin, D., Congr. Geol. Internat. Compt. Rend. 19th Session, Algeria, 1932, 11, 13 (1953).

${ }^{5}$ Lenoble, C.R. Acad. Sci., Paris, 238 (1054).

- Thompson, M. E., Geol. Surv. Bull. 988-D (1953).

\section{Duration and Band-width of Short-lived Transients in Solar Noise}

THE duration of small bursts in solar radio noise at $400 \mathrm{Mc}$ /s. has been stated ${ }^{1}$ recently to be $0 \cdot 18 \pm$ $0.03 \mathrm{sec}$. This value was a maximum in a histogram. On days with an intense small-scale activity, the material obtained is so abundant that reliable histograms can be obtained for periods as short as two hours. Fig. 1 shows an example of such a set. The shift of the maximum and of the entire curve is undoubtedly significant in most cases, and it should be possible to correlate it with a similar shift in the circumstances in which the bursts originate.

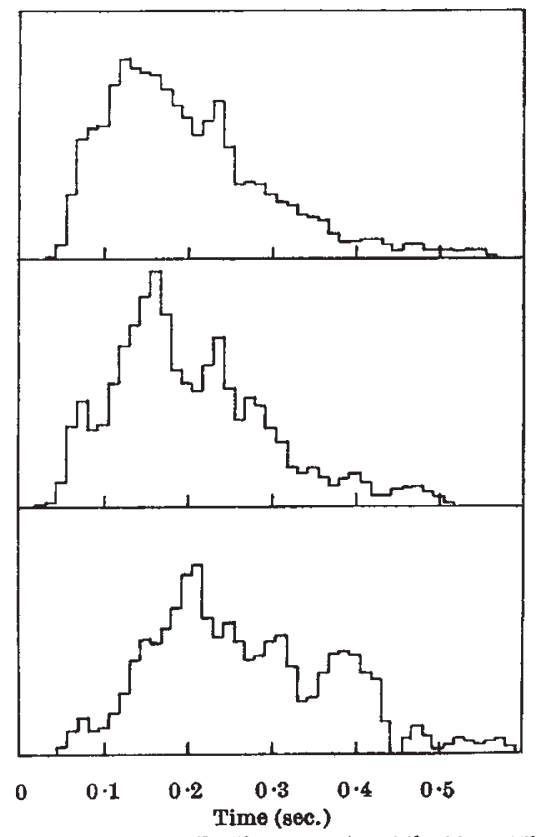

Fig. 1. Top, $15 \mathrm{~h} .26 \mathrm{~m} .-15 \mathrm{~h} .57 \mathrm{~m}$.; centre, $14 \mathrm{~h} .00 \mathrm{~m},-15 \mathrm{~h} .19 \mathrm{~m}$ bottom, 11h. 00m.-12h. $24 \mathrm{~m}$. 